Teresa Martins de Oliveira*

Universidade do Porto - ILC

\title{
Flucht aus Frankreich, 1940 [Fuga da França] de Marianne Loring. Memórias: entre a fuga coletiva e o percurso individual $^{1}$
}

Resumo:

Em 1940, a direção do partido social-democrata alemão que se refugiara em Paris depois de anos de exílio em Praga, vê-se obrigada a partir de novo, numa fuga cuja rota atravessa a França, Espanha e Portugal. Do grupo fazia parte a jovem Marianne Loring, filha de um destacado membro do partido, que descreve essa fuga num texto memorialista, que apenas será dado à estampa 50 anos depois. No meu artigo focarei não só as memórias da autora sobre a fuga de todo o grupo, como também das suas vivências pessoais, que evocam um romance de formação.

Palavras-chave:

Marianne Loring, memória, exílio

Abstract:

In 1940, the leaders of the Social Democratic Party of Germany which had taken refuge in Paris after years of exile in Prague, are forced to leave again, on an escape whose route crosses France, Spain and Portugal. The group included the young Marianne Loring, daughter of a prominent party member, who describes this escape in her memoirs, which were printed 50 years later. In my article, I will focus not only on the author's memoirs of the escape of the group, but also on her personal experiences, which evoke an education novel.

Keywords:

Marianne Loring, memory, exile 
Em grande parte devido às tragédias ligadas aos surtos migratórios contemporâneos, os caminhos de fuga e o motivo da passagem têm vindo a tornar-se prioritários para os Estudos sobre o Exílio, que juntamente com os Estudos de Memória têm revisitado essas experiências. No nr. ${ }^{0} 35$ do Anuário dos Estudos sobre o Exílio [Exilforschung], publicado em 2017, que leva o título promissor de Passagen des Exils [Passagens do exílio] e se debruça sobre percursos exílicos do século XX e XXI, explica-se: "Com o conceito de 'passagens' referimo-nos ao estado de liminaridade em que entram os/as migrantes, fugitivos e exilados entre a partida da sua terra de origem e a chegada à terra de destino ou às diferentes paragens intercalares" ["Mit dem Begriff der Passagen ist der Schwellenzustand gemeint, in den Migrant*innen, Geflüchtete und Exilanten zwischen Abreise aus ihrem Herkunftsland und Ankunft in einem Zielland oder den verschidenen Zwischenstopps eintreten] e propõe-se discutir "rotas como espaços de experiência culturais numa perspetiva interdisciplinar" (Dogramaci/Otto 2017: 7). O conceito de liminaridade vem, assim, juntar-se à ideia da mobilidade, diversificada numa perspetiva ampla e plural, que vinha sabidamente ganhando relevância nos estudos culturais, literários e de memória. ${ }^{2}$

Com estes novos enfoques, rotas de fuga como aquela que atravessou Portugal durante a Segunda Guerra Mundial e as estadas, por vezes muito curtas, dos refugiados no nosso país não só podem ganhar e têm ganhado novo protagonismo, como têm vindo a ser revisitadas enquanto experiências de deslocação, de exclusão, de suspensão e de fronteira (territorial, político-ideológica, linguística, cultural, humana) (Passagen). Provam-no tanto o crescente número de trabalhos de investigação no âmbito quer da história, quer da cultura e da literatura, que têm dado origem a importantes publicações ${ }^{3}$ e exposições (p. ex. nos lugares de residência fixa dos refugiados em Portugal), como também as fundações recentes dos museus da Fronteira em Vilar Formoso e do Holocausto no Porto.

Importante será (re)descobrir e também continuar a estudar as obras de muitos intelectuais e artistas que viveram o exílio e o tematizam, e estudar a forma como experiências colhidas nesses contactos de passagem contaminaram trabalhos futuros, em criações verdadeiramente transculturais. Em outros casos, as vivências exílicas transformaram fugitivos e exilados em criadores, que buscaram na arte/escrita uma forma de fixar, expurgar ou sublimar vivências, constituindo-se, de certa forma, como uma variação da tão dolorosamente célebre necessidade de "dar testemunho" sentida pelos sobreviventes dos campos de concentração e extermínio.

É nesta perspetiva que pretendo olhar o texto autobiográfico de Marianne Loring Flucht aus Frankreich 1940. Die Vertreibung deutscher Sozialdemokraten aus dem Exil [Fuga da França 1940. A expulsão do exílio de social-democratas alemães] , que descreve a fuga que a autora empreendeu juntamente com os pais e, em grande parte do percurso, com outros dos principais dirigentes do partido social-democrata alemão. ${ }^{4}$ Interessa-me o depoimento de Loring enquanto relato de uma fuga desde a França até aos EUA, o destaque conferido à travessia errática da França e a passagem por Espanha e Portugal, passagem à qual pode ser atribuído um caráter de certa forma exemplar no que respeita à rota percorrida e a muitas das vicissitudes experienciadas. A obra vai, 
todavia, muito para além da descrição de um percurso físico através do espaço, situações sociopolíticas e culturais, revelando-se enquanto relato da transformação identitária da heroína/ autora, (da condição de filha protegida a refugiada e, por fim, acolhida) como se torna claro pelas referências e memórias que convoca, nomeadamente pelo papel da ideia e da memória da Europa.

Escrito nos EUA no Verão de 1941, um ano depois das vivências que retrata - Marianne tem 17 anos à data da conclusão do manuscrito -, o relato da fuga vem a ser publicado apenas 50 anos depois, em 1991, integrando, assim, o boom de publicações de textos autobiográficos referentes às vivências da Segunda Guerra Mundial dos anos 80 e 90. No prefácio, a autora explica a publicação tardia com a vontade de preservar figuras públicas e as suas famílias, sobre quem achava ter tecido opiniões severas (FaF 25). Num comentário introdutório, o editor garante que nem ele nem a autora procederam a qualquer alteração do texto (FaF 21) e na minha interpretação parto da bondade desse depoimento.

Trata-se, portanto, de um texto autobiográfico de uma adolescente, e nessa qualidade, alguma crítica o têm equacionado (sem grande proveito, aliás) quer com 0 Diário de Anne Frank (1947) quer com weiter leben [continuar a viver] 5 (1992) de Ruth Klüger. Mais comum, até porque referido tanto na contra-capa do livro como no subtítulo, é a menção ao contributo deste relato para a história da expulsão dos sociais-democratas do exílio francês, da qual existem, ainda, outros relatos autobiográficos, nomeadamente de Friedrich Stampfer e de Elsbeth Weichmann, política e futura deputada do SPD, mulher de Herbert Weichman, membro da direção do SPD.

De facto, Marianne era filha do jornalista e político do SPD Friedrich Stampfer (18741957), ${ }^{6}$ oriundo de uma família austro-húngara de origem judaica secularizada. Conhecido opositor de Hitler, membro da direção do partido social-democrata alemão, deputado no Reichstag da República de Weimar e redator-chefe dos jornais Vorwärts [Avante] e Neuer Vorwärts [Novo Avante], Stampfer teve um papel destacado na criação e divulgação das orientações programáticas do partido, e o seu destino (e com ele o da sua filha) é marcado pela história do SPD, nomeadamente durante o tempo do nacional-socialismo.

Lembre-se como o SPD, tendo-se oposto tanto a trilhar um caminho de oposição ilegal como a organizar essa oposição a partir do exterior na fase inicial da escalada do poder pelos nazis, ${ }^{7}$ vem a ser ilegalizado em 22 de junho de 1933. Todavia, já anteriormente, no início de maio de 1933, o ataque de Hitler aos sindicatos tinha levado a direção do SPD a transferir para o exterior, a contragosto de muitos deles, alguns dos seus membros diretivos mais ameaçados: Cummerl e Stampfer primeiro, seguidos de Wels, Vogel, Ollenhauer e Hertz, ao mesmo tempo que fugiam da Alemanha outros membros do partido (Plum 1970: 416). Com parte da direção radicada em Praga (depois de uma curta vilegiatura em Saarbrücken), aí se funda o SOPADE (o SPD no exílio), contestado, embora, na sua pretensão de ser reconhecido como representante único de todo o partido, tanto pelos membros da direção que haviam permanecido na Alemanha como pelas fações mais à esquerda do partido. ${ }^{8} \mathrm{~A}$ partir de Praga, o SOPADE empenha-se em denunciar os crimes do nacional-socialismo e em orientar atividades de resistência na Alemanha. ${ }^{9}$ 
A escalada dos ataques de Hitler à Checoslováquia dita a mudança do SOPADE para Paris, na Primavera de 1938. Dois anos e uns tantos desentendimentos internos depois, com alguns membros (p.ex. Vogel e Ollenhauer) ainda retidos em campos de internamento para estrangeiros inimigos, a direção do partido encontra-se de novo em fuga às tropas de Hitler, que avançam pela França ocupada. Depois de meses de incertezas, conseguem com o apoio dos EUA e a partir do sul de França, onde todos se vêm a reunir, atravessar Espanha e Portugal e emigrar: uns (Stampfer e Weichmann) para os EUA e outros (Vogel, Ollenhauer, Geyer e Heine) para Inglaterra, onde desde antes da guerra se haviam criado condições para albergar um centro do SPD no exílio..$^{10}$ Foi essa fuga a partir de Paris de alguns dos mais destacados membros do SOPADE e suas famílias, que Marianne viveu e descreve no seu texto, sendo que destes apenas Rinner, Vogel, Ollenhauer e Weichmann e famílias, bem como a mulher e as filhas de Geyer viriam a encontrar-se em Lisboa. Breitscheid e Hilferding decidem ficar em França, decisão que os conduzirá à morte, compartilhando com os outros apenas a primeira parte da viagem, enquanto Geyer chegará a Lisboa mais tarde.

Antes de me concentrar no percurso de fuga descrito no texto, não quero deixar de chamar a atenção para o facto de que o objeto da minha análise é um texto literário e que assim o considerarei, muito embora a crítica situe textos autobiográficos na orla da ficcionalidade, e o leitor tenda a privilegiar neles, muitas vezes justamente, o conteúdo, não criando grandes expectativas no que respeita à sua qualidade literária. No que toca ao relato de Marianne Loring, seria injusto esquecer, todavia, que se trata de um texto que não fica atrás de obras análogas de autores muito menos jovens. A vasta cultura literária e artística própria da educação das jovens da burguesia culta da época revela-se numa escrita fluida e elegante, nas muitas referências literárias e culturais, bem como em relações intertextuais com obras de autores principalmente alemães e franceses, e ainda em subtis comentários metatextuais, ou na contaminação com diferentes subgéneros narrativos, questões a que breve e pontualmente voltarei.

No que diz respeito à rota de fuga, a experiência descrita por Marianne Loring pode ser encarada, sob muitas perspetivas, como um exemplo das vivências de muitos alemães e austríacos conhecidos ou anónimos que, vindos de França, atravessaram a Península Ibérica em fuga à barbárie nazi. Pese embora o facto de viajarem em grupo (são cerca de 20 pessoas, homens, mulheres e crianças) e de a identidade destacada dos seus membros (com o nome inscrito nas listas de procurados pelos nazis) constituir um risco acrescido, são muitas as vivências de valor quase paradigmático: as dificuldades em arranjar transportes e alojamentos, a necessidade de obter autorização para qualquer permanência, para qualquer deslocação, por mais curta que fosse, o pesadelo de encontrar um país de acolhimento e da obtenção dos vistos para deixar a Europa (visto de saída de França, de passagem por Espanha e por Portugal, de saída para um país ultramarino), a busca errática por uma fronteira de saída, a desorientação generalizada, a falta de informações seguras, permanentemente cruzadas com boatos alarmistas, e o medo de cair nas mãos da Gestapo.

Em 28 de Maio de 1940, i.e., depois da capitulação do exército belga e do início da Batalha de Dunquerque, Marianne sai de Paris convencida de que em breve estarão de volta: o pai é 
incumbido de preparar a instalação no sul da França dos membros do SOPADE, alguns ainda internados em campos de refugiados. Logo após a primeira noite numa Bordéus repleta de fugitivos, obrigada a pernoitar com os pais nos bancos de um café, consciencializa-se da sua nova condição de exilada. Segue-se um percurso marcado por altos e baixos, avanços e compassos de espera (em Agen e Castres), e a nova fuga, após a invasão da França, num clímax de desespero, na tentativa primeiro de chegar a Bordéus, e daí a Inglaterra, depois procurando alcançar Sète, porto na costa mediterrânica, na esperança, também ela gorada, de atravessar para África. Agen, Tonneins, Castres, Montpellier, St. Pon, são locais de passagem. Após três dias a dormir numa camioneta cheia de gente, regressam a Castres, onde, depois de semanas ensombradas pela ameaça de serem entregues aos nacional-socialistas pelas autoridades francesas, Stampfer é contactado pelo jornalista norte-americano Frank Bohn que, ao serviço do American Joint Labor Committee e a partir de Marselha, ainda antes da chegada de Varian Fry, levava a cabo a difícil missão de salvar funcionários de sindicatos e socialistas europeus. É ele quem, juntamente com o cônsul americano, providencia por fim os documentos que permitirão a fuga pela Península Ibérica. A partir de Marselha, contornadas novas dificuldades e compassos de espera, partem de comboio para Espanha e depois para Portugal, onde chegam em setembro de 1940. Um mês depois, seguem para Nova Iorque, a bordo do navio Nea Hellas.

Com a honestidade interior e a radicalidade judicativa próprias da adolescência, Marianne não perde a capacidade de se indignar: com a desconfiança e tensão que crescem entre os membros do grupo; com as pequenas quebras de solidariedade; com as notícias sensacionalistas e consigo própria. A sua consciência social desperta e a capacidade de compaixão acordam nela uma má consciência face às condições privilegiadas em que, apesar de tudo, se dá a sua fuga, e face ao sentimento de traição ao abandonar uma Europa devastada e em guerra. Em todo o texto perpassa ainda a preocupação de Marianne com o pai, com a sua saúde frágil e com o sofrimento que nele pressente. Ao lado destes momentos de maior tensão, há outros vividos numa espécie de suspensão, em que os percursos de fuga são sentidos quase como um passeio turístico e cuja descrição evoca um relato de viagem.

Comum a outras memórias de exilados que passaram por Portugal é também a (pouca) atenção que a economia do texto dedica ao nosso país. Seguindo uma lógica estritamente cronológica, Marianne Loring relata as vivências em França nos 34 primeiros capítulos, dedicando os últimos 5 capítulos à Península Ibérica (2 à travessia por Espanha, 3 a Portugal) ${ }^{11} \mathrm{e}$ ainda 1 à passagem para os EUA. É comum ouvir-se entre nós pela boca de investigadores que privilegiam uma perspetiva imagológica a frustração pela pouca atenção que os relatos dos refugiados dedicaram ao nosso país, do qual transmitem uma imagem que se esgota em motivos repetidos: sensação de segurança em Portugal vs. ameaça pressentida em Espanha; a alegria e a abundância vividas na capital portuguesa: profusão de víveres, de luz, de calor e de barulho; a beleza da cidade de Lisboa, a pobreza da população e a sua simpatia, embora por vezes movida por interesses económicos, etc. De facto, tal como a leitura de um texto literário trai a enciclopédia de leitura de quem dele se apropria, também o olhar breve lançado sobre o Outro revela frequentemente mais de quem vê do que de quem é visto. 
O mesmo acontece com o relato de Marianne Loring no que concerne à descrição da passagem pela Península Ibérica. Fazendo-se, muito provavelmente, eco do pensamento dos sociais-democratas, que, como outros antifascistas alemães, tinham experienciado a guerra civil espanhola como um prenúncio da $2 .{ }^{\mathrm{a}}$ Guerra Mundial e viam em Franco o émulo de Hitler, e refletindo o medo real que os membros do seu grupo naturalmente sentiam de serem descobertos na sua identidade, presos e entregues à Alemanha, Loring cria uma imagem de Espanha altamente disfórica: ensombrada pela omnipresença de Franco (com o retrato emoldurado em todas as repartições públicas), referido não só como culpado da destruição generalizada (de casas e monumentos a estátuas religiosas mutiladas), mas também do desleixo dos escombros não removidos, da miséria das populações, do comportamento relaxado e criminoso de funcionários, que roubavam dinheiro aos refugiados e atentavam contra a sua dignidade em revistas físicas e injustificadas esperas. E mesmo a paisagem, que entre Barcelona e Madrid é descrita como tendo trechos muito bonitos e que por vezes lembra a Marianne um cenário da Carmen de Bizet, torna-se especialmente desoladora, ominosa até, no percurso entre Madrid e Valência [de Alcântara] ${ }^{12}$ (FaF, 122-124).

Por oposição, em Portugal, os funcionários alfandegários são "criados de lavoura bonitos como estampas" e respeitadores, os procedimentos organizados e confiáveis e a imagem da aldeia fronteiriça é branca e alegre, em contraste com a sujidade espanhola (FaF 126). Lisboa é descrita com algum pormenor, numa toada de panfleto turístico, como uma das mais belas cidades do mundo, e a abundância de víveres, tal como Loring a descreve, é também citada em textos críticos que tratam a imagem de Portugal nos textos de refugiados (p.ex. Heine Teixeira 2001: 673).

E, todavia, em breve a estada na cidade se lhe torna pesada e acorda nela a ânsia de partir. As razões que aduz remetem de novo para topos da literatura dos exilados: primeiro o ambiente tenso entre os refugiados, com as suas pequenas querelas e as bobards (a versão epocal das atuais fake news), que tanto a incomodam desde França. Depois, a situação feminina em Portugal, de que se apercebe pelo número reduzido de mulheres nas ruas e pelos piropos desagradáveis a que se vê exposta e também pelo relato de uma amiga alemã a viver em Lisboa há algum tempo. As referências à falta de instrução e cultura das mulheres portuguesas e à sua dependência dos homens numa sociedade opressiva e claustrada aproximam os comentários de Marianne Loring dos de outras refugiadas cultas e esclarecidas, oriundas de uma Alemanha onde as mulheres gozavam de muito maior liberdade e que se chocavam com o atraso em que vivia a população feminina de Portugal.

Entrelaçado na descrição do percurso físico da viagem surge o retrato do percurso interior da autora. Lembre-se, a este propósito, que, como dissemos, Loring começa a escrever o seu relato 6 meses depois de chegar a Nova Iorque, e sabemos, como dizem os Estudos de Memória, que as recordações são um misto de reminiscências do passado e dos sentimentos e das necessidades do presente. Correspondem também, como enfatiza Nünning, a uma seleção e a uma organização que não é imune a outros textos preexistentes (Nünning 2010: 417-153). Assim, o percurso evolutivo que Marianne Loring descreve mostra-a na passagem de um estado 
de inocência para uma consciencialização, alcançada através de momentos de prova(ção) e que termina com a chegada ao porto seguro que é Nova Iorque, percurso esse que evoca claramente o amadurecimento próprio do herói de um romance de formação.

No caminho de reflexão interior da jovem Marianne, adquirem especial destaque os momentos de passagem de fronteira (refiro-me à saída de França e ao passar dos Pirenéus, à entrada em Portugal, à partida de Lisboa e à viagem de barco com chegada aos EUA), como é, aliás, frequente em textos deste tipo, já que é nas passagens de fronteira que a polissemia do conceito da passagem se parece adensar. Numa dimensão mais factual e histórica, o cruzar de fronteiras retrata o adensar das dificuldades reais e dos perigos vividos generalizadamente pelo migrante, quer pela quantidade de documentação exigida, quase impossível de reunir, quer pela quantidade de situações de imponderabilidade e aleatoriedade discricionária a que os fugitivos estavam sujeitos (mudanças constantes nas condições de abertura e cruzamento das fronteiras; exposição à autoridade e a arbitrariedades de toda a ordem), quer ainda pelos imbricados estratagemas a que se viam obrigados a recorrer para contornar estas dificuldades.

Também no percurso de reflexão interior, a passagem de fronteira é um momento relevante, por alguns comparada a um verdadeiro rito de passagem. No texto de Marianne Loring, em todas as passagens de fronteira importa realçar o papel atribuído à ideia da Europa: primeiro como refúgio identitário e depois na qualidade de moving memory, ${ }^{13}$ tornando-se, nesta medida, uma verdadeira chiffre integradora, questão a que voltarei.

Lembremos que Marianne Stampfer, nascida na Berlim da República de Weimar, é alemã de nascimento, embora filha de pai austro-húngaro nacionalizado alemão, que, por ser oriundo da Morávia, não teve dificuldade em obter para a família o passaporte checo. Interessante é notar que nunca ao longo do texto Marianne se atribui a si própria uma nacionalidade específica, mas face a perguntas embaraçosas sobre a sua origem, apresenta-se e/ou é apresentada como checoslovaca. Por outro lado, Marianne descreve com ironia o seu grupo como "uma horda de alemães" (FaF, 79), mas os alemães são também, as mais das vezes, os nazis de quem foge, os sanguinários invasores da França. A esta cabe todo o amor da jovem Marianne, como ela própria o afirma, e como o revelam largas passagens de empática solidariedade, num discurso empolado que parece ter bebido do fervor patriótico de autores como Victor Hugo ou Lamartine, que cita frequentemente. Trata-se, todavia, de amor a uma França idealizada, pátria da civilização e da liberdade, uma França sem franceses, aos quais atribui, aliás, numa visão preconceituosa, falta de rigor e de capacidade organizativa, pouca fiabilidade e seriedade e falta de patriotismo egoísta e comodista $(\mathrm{FaF}, 48)$.

Interessante será também referir os (chocantes) comentários de Marianne sobre os soldados negros que integram o exército francês, que descreve como esfarrapado e destroçado e aparentemente incapaz de conter os ímpetos criminosos de Hitler, pelo que neles ecoa de uma superioridade rácica sabidamente comum na perspetiva alemã face à integração pela França

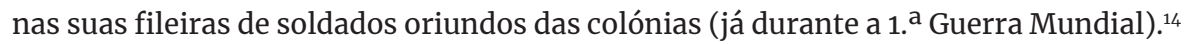

Na véspera da partida de França, num discurso altamente emotivo, Marianne despede-se da sua infância protegida e da sua pátria "Europa". Note-se como nesta geografia afetiva 
Cadernos de Literatura Comparada

Flucht aus Frankreich, 1940 [Fuga da França] de Marianne Loring

Espanha e Portugal são sentidos como "terra de ninguém", equiparados ao oceano (ideia que será revista, pelo menos parcialmente depois de os percorrer).

Die letzte Nacht! Hier, auf dieser Seite der Berge lag meine Kindheit und meine Jugend. Drüben, jenseits der Berge, mein weiteres Leben, dicht verhüllt vom Schleier der Zukunft. Hier, auf dieser Seite, liegt mein Europa, meine Heimat, mein blutendes leidendes Vaterland. Drüben, jenseits der Berge, liegt Amerika, glücklich und unberührt von dem Brand, der Europa in Flammen steckt. Die letzte Nacht. (FaF, 118)

[A última noite! Aqui, deste lado dos montes ficavam a minha infância e a minha juventude. Do outro lado, para lá dos montes, o resto da minha vida, pesadamente envolta no véu do futuro. Aqui, deste lado, fica a minha Europa, a minha pátria, a minha pátria sangrenta e sofredora. Do outro lado, para lá dos montes, fica a América, feliz e intocada pelo incêndio que pôs a Europa em chamas. A última noite.]

Em Lisboa, no momento da partida e já a bordo do "Nea Hellas", a autora/narradora retoma a ideia da fronteira da Europa, que coloca agora na orla da costa portuguesa e reflete, com a consciência pesada, sobre aquilo que sente como uma deserção.

Es ist eine stille Nacht. Nichts darf die Andacht dieser Stunde stören. Fünf Meter von uns entfernt liegt Europa, unsere blutende, verbrennende, zerstörte Heimat. Auf dem Land, fünf Meter von uns, bin ich geboren. Mit dem Land ist jede Faser meines Herzens verbunden. Europa ist ich; ich bin Europa, Alles, was ich liebe, alles, das mich liebt, ist in Europa. Europa war für mich das Leben, Europa ist für mich Freude und Schmerz, Liebe und Hass, Glück und Unglück.

Und wir? Wir verlassen Europa. Wir desertieren aus Europas Unglück. In der Nacht schleichen wir uns fort.

Ein Sirenenstoss! Was willst du, abscheuliche Stimme? Warum zerreisst du die heilige Stille dieser Nacht?

Langsam, als ob sie sich schäme, geht die Landungsbrücke hoch. Wir sind von Europa abgeschnitten, und die fünf Meter werden zu einer unüberbrückbaren weiten Ferne...

Zum zweitenmal erklingt dein Klagelaut, Sirene? Noch nicht, noch nicht...

Aus den fünf Metern werden sechs und sieben und acht; so sei es denn. Lieb Heimatland, ade!

Leise und langsam gleitet die «Nea Hellas» den Fluss hinunter, dem offenen Meere zu. Wie ein Märchenland zieht die hell erleuchtete Ausstellung, an uns vorbei.

Weiter und weiter gleiten wir, bis die Lichter von Lissabon in den Sternenhimmel hineinwachsen, weiter bis der Horizont in ein gleichmässes Schwarz getaucht ist.

Hinten, weit hinten, wo die letzten Lichter ins Wasser tauchten, war Europa. Und um uns ist Nacht. (FaF, 130)

[É uma noite serena. Nada deve turvar a devoção desta hora. A cinco metros de nós fica a Europa, a nossa pátria sangrenta, ardente, destruída. Na terra, a cinco metros de nós, eu nasci. Com essa terra se liga cada fimbria do meu coração. Europa é eu; eu sou Europa. Tudo quanto amo, tudo 
quanto me ama está na Europa. A Europa foi para mim a vida, Europa é para mim alegria e tristeza, amor e ódio, felicidade e infelicidade.

E nós? Nós abandonamos a Europa. Desertamos da infelicidade da Europa. Escapulimo-nos na noite.

Um toque das sirenes! Que queres, voz tenebrosa? Porque rasgas o silêncio sagrado desta noite? Devagar, como se se envergonhasse, ergue-se a ponte de desembarque. Estamos desligados da Europa, e os cinco metros transformam-se numa lonjura longa e insuperável...

O som do teu lamento ecoa pela segunda vez, sirene? Ainda não, ainda não ...

Os cinco metros fazem-se seis e sete e oito: então, seja. Querida pátria, adeus!

Suave e lentamente, o «Nea Hellas» desliza pelo rio abaixo em direção ao mar aberto. Como um país de conto de fadas passa por nós a exposição claramente iluminada. Deslizamos para mais e mais longe até que as luzes de Lisboa se perdem no céu estrelado, para mais longe, até que o horizonte mergulha numa escuridão uniforme. Lá atrás, muito lá atrás, onde as últimas luzes mergulham na água, era a Europa. E à nossa volta é noite].

O leitor não pode deixar de pensar na despedida de Lisboa de Heinrich Mann, de Döblin e de tantos outros, tornada topos da partida da capital portuguesa na literatura de exílio. Lembra, igualmente, os múltiplos e nalguns casos ambivalentes projetos de uma Europa unida, defendidos nos anos 40 e 50 por tantos escritores de língua alemã, de orientações políticas bem diferentes, que iam de um humanismo socialista e da ideia de uma Europa pacificada e livre à exploração do potencial de diluição de uma culpa alemã que não queriam assumir (Zylinski 2011: 7-30).

Lembre-se, também, pela influência que poderá ter na formação do pensamento de Marianne Loring, a importância da ideia da Europa no discurso programático do SPD. De facto, já no ano de 1925 o congresso do SPD fora dominado pela ideia da criação dos Estados Unidos da Europa, e muito embora a ascensão de Hitler ao poder e o exílio tenham por momentos redirecionado as prioridades do SOPADE, esta ideia está no centro das discussões sobre a Alemanha na pós-derrota de Hitler. Pesem embora algumas divergências, nomeadamente no que diz respeito ao equilíbrio e ao papel das diferentes potências europeias e à integração da Europa na geopolítica internacional, a ideia dos Estados Unidos da Europa de inspiração social-democrata afigura-se garante de justiça internacional e paz. Nesta discussão é de destacar (ao lado de Hilferding, Breitscheid, Geyer e Bienstock) o papel de Friedrich Stampfer na promoção da ideia de uma Europa federal e democrática como força de oposição ao nacional-socialismo e a políticas de matriz totalitária (Schilmar 2004: 50-58). ${ }^{15}$

Todavia, no texto de Marianne Loring a ideia da Europa não parece integrar um projeto político específico, que nada no texto permite evocar. A sua inspiração aproxima-se, antes, da ideia talvez não muito diferente da do pai, de um mundo de valores superiores e irrevogáveis da cultura europeia na qual Marianne se refugia, mas que tinge com a apropriação pessoal de um universo marcadamente romântico. Leia-se a descrição onírica com que termina a primeira passagem que citei e em que os espíritos da infância da protagonista, figuras grotescas e ambivalentes, sobem das profundezas dos abismos das montanhas para se despedirem dela: 
Die Nebel hinter den Bergen ballten sich: deutliche Gestalten kamen hervor, aus den Tiefen des Meeres und den Schluchten der Gebirge. Wehmütige Gestalten, drohende Formen, klagende Geister, weinende Köpfe, hohnlachende Züge, liebende Augen - (...) die Geister meiner Kindheit. Mit ihren kalten, heissen (...) Lippen drückten sie den Abschiedskuss auf meiner Stirn (...) und füllten mein Zimmer, und füllten meine Seele, und sie hoben mich empor und trugen mich hinaus, hinweg über die Berge, hinüber in die Eiswüste der kalten, der neuen Zukunft - und sie gingen zurück, zurück über die Berge, die die Grenze waren, zwischen Vergangenheit und Zukunft. (FaF, 119)

[As brumas atrás dos montes acumulavam-se: figuras nítidas apareciam, vindas das profundezas do mar e dos desfiladeiros das montanhas. Figuras doridas, formas ameaçadoras, espíritos queixosos, cabeças chorosas, esgares ridentes de escárnio, olhos amantes - (...) os espíritos da minha infância. Com os seus lábios frios, quentes (...) imprimiam o beijo de despedida na minha fronte (...) e enchiam o meu quarto, e enchiam a minha alma, e levantavam-me e levavam-me lá para fora, para longe daqui, para lá dos montes, para lá, no deserto gelado do novo e frio futuro - e voltavam para trás, para trás por sobre os montes, que faziam fronteira entre passado e futuro].

Neste contexto, especialmente interessante se me afigura a viragem final que o motivo da Europa sofre, tanto na projeção identitária que a autora/narradora constrói para si, como, ao nível da economia textual, enquanto conclusão do percurso formativo que atrás mencionei. À chegada a Nova Iorque, e depois de dias de desespero e desorientação no mar, lê-se:

Hoch hielt die Freiheitsstatue die brennende Fackel in die Luft. Ihr Blick ist denen zugewendet, die, um Verfolgung und Tod zu entrinnen, zu den Ufern des Landes kommen, wo ihr Geist weilt. Wehmütig schweift ihr Blick über das Wasser, dorthin, wo Europa liegt. Wie wir, ist sie ein Kind Europas, wie wir, ist sie von dort vertrieben.

O Freiheit, erhabene Göttin, möge dein Lächeln wieder ein Kontinent erhellen, der jetzt in den Nebeln der Sklaverei begraben liegt!

Höher steigt die Sonne - und dort, dort hinten, wo die Nebelschleier reissen, wachsen die silbergrauen Steinriesen, vom schwachen Sonnenschein erhellt, aus der Nacht. Ein Bild der Kraft und der Macht, recken sie sich zum blauen Himmel hinauf.

[...]

Ich danke dir, o mein Schicksal, dass du mich geführt hast durch die Nacht und den Nebel der Verzweiflung, in den neuen Tag des Lebens und der Freiheit. (FaF, 132)

[A estátua da liberdade levantava o facho ardente bem alto no ar. O seu olhar vira-se para aqueles que, para escapar à perseguição e à morte, chegaram às costas do país onde o seu espírito impera. Dolorido, o seu olhar paira sobre as águas, até lá, onde fica a Europa. Como nós, ela é uma filha da Europa, como nós, foi expulsa de lá. Oh, liberdade, deusa sublime, possa o teu sorriso iluminar de novo um continente que agora se encontra soterrado nas névoas da escravidão! 
O sol sobe mais alto - e ali, ali atrás, onde se rasgam os véus do nevoeiro, crescem da noite os gigantes de pedra cinza-prateados, iluminados pelo fraco brilho do sol. Uma imagem da força e do poder, esticam-se para cima, em direção ao céu azul.

[...]

Agradeço-te, oh meu destino, que me tenhas conduzido através da noite e do nevoeiro do desespero, até ao novo dia da vida e da liberdade]

Depois de uma viagem vivida como rito de passagem, em que o sofrimento dá lugar à expectativa e à esperança, é à memória da Europa que Marianne "se agarra". A estátua da liberdade enquanto metonímia dos próprios EUA é apresentada como filha livre da Europa, representante dos seus valores de humanismo e liberdade, e, nessa medida, é atualizada como companheira de infortúnio dos refugiados. Simultaneamente, esta memória torna-se também um elemento capaz de mover/inspirar a heroína no seu processo de integração.

Esta memória da Europa, que na sua capacidade dupla nos permite evocar o conceito de dupla aceção moving memory (memória simultaneamente "em movimento" [on the move] e "capaz de mover" [moving]) (Erll 2017), torna-se uma verdadeira memória integradora. Se nas duas primeiras experiências de passagem de fronteira a memória da Europa parece refletir uma atitude desligada da realidade e escapista, ela marca, na sua nova viragem, a passagem para uma atitude de esperança e expectativa.

O texto de Marianne Loring termina numa interessante mistura evocativa e prospetiva, em que se cruzam uma toada hínica e elegíaca de louvor à liberdade com uma forma de secularização de regozijo bíblico, revestindo-se a chegada à América de uma sabor de chegada à Terra Prometida. Registe-se, na descrição da silhueta da cidade de Nova Iorque, a referência ao "poder e força" ["Macht und Kraft"] (FaF, 132) da cidade, na qual se revela uma América forte, poderosa e voltada para o futuro.

A fechar o relato, Loring faz um balanço positivo do que foi a sua vida até ao momento: uma vida "cheia de acontecimentos, um vida pesada, por vezes, mas bonita" (FaF, 132) e remete de novo para a literatura, que tanto marcava a sua forma de ver o mundo, para perspetivar o futuro: "à minha frente há apenas páginas em branco, por escrever" (FaF, 132). E, de facto é pelo estudo da literatura inglesa que Marianne Stampfer vem a optar, tendo obtido um B. A. do Hunter College em New York City. Regressada à Alemanha, onde vive em Munique cerca de dois anos, regressa já casada aos EUA e radica-se na Califórnia até ao fim da vida. 
Cadernos de Literatura Comparada

Flucht aus Frankreich, 1940 [Fuga da França] de Marianne Loring

\section{NOTAS}

* Teresa Martins de Oliveira é Professora Associada aposentada do Departamento de Estudos Germanísticos da Faculdade de Letras da Universidade do Porto, onde lecionou nas áreas da Literatura e da Cultura Alemãs em cursos de licenciatura, mestrado e doutoramento. Doutorada em Literatura Alemã (1998) com uma tese de orientação comparatista, tem-se dedicado à literatura de expressão alemã (do século XIX até à contemporaneidade), com especial enfoque nos Estudos de Género, nos Estudos do Holocausto e da Memória e também em Estudos sobre a Europa. É membro da I\&D - Instituto de Literatura Comparada Margarida Losa, onde integra o projeto Inter/Transculturalidades, e onde criou, juntamente com Maria Antónia Gaspar Teixeira e Gonçalo Vilas-Boas a base de dados "Passagen. Fugindo ao Holocausto: artistas e intelectuais de língua alemã no exílio português". Tem ainda colaborado em vários projetos de investigação nacionais e internacionais.

${ }^{1}$ Uma versão reduzida deste texto, em língua inglesa, com o titulo "Marianne Loring's Escape from France (1940)" foi apresentada na conferência online "Transcultural Mobilities and Memories", que teve lugar na Universidade do Minho, entre 15 e 16 de abril de 2021 .

${ }^{2}$ Sobre a ideia da mobilidade/do movimento e da conexão relacional entre espaços geográficos, culturas, disciplinas, etc., sobre a sua relevância na formação do eu e sobre a sua representação nas diferentes literaturas, vd. Ottmar Ette (2001), Literatur in Bewegung. Raum und Dynamik grenzüberschreitenden Schreibens in Europa und Amerika, Göttingen, Verbrück Wissenschaft; O.E. (2005), ZwischenWeltenSchreiben. Literaturen ohne festen Wohnsitz, Berlin, Kulturverlag Kadmos; O.E. (2012),TransArea. Eine literarische Globalisierungsgeschichte, Berlin/Boston, de Gruyter; O.E. (2017), WeltFraktale: Wege durch die Literaturen der Welt, Sttutgart, J.B. Metzler. Do mesmo autor, em português, leia-se, "Pensar o futuro: a poética do movimento nos Estudos de Transárea", Alea: estudos neolatinos v. 18, n.2, p.192-209, 2016. Disponível em: » https://dx.doi.org/10.1590/1517-106X/182-192.

${ }^{3}$ Sobre o conceito de «moving memory», vd., p.ex., Roundtable 'Moving Memory' with A. Erll, D. Levy, A. Rigney, M. Rothberg and A. Sierp, in: «Thinking through the Future of Memory», Memory Studies Association, 3-5 December 2016, Amsterdam, CONFERENCE 2016 - Memory Studies Association.

Entre as muitas publicações sobre a temática dos refugiados da Segunda Guerra Mundial em Portugal, há a destacar, entre outras, diferentes obras de Irene Flunser Pimentel, Esther Mucznik, Ansgar Schäfer e Patrik von zur Mühlen. Refira-se ainda a base de dados Passagen, Artistas e intelectuais de língua alemã no exílio português, de acesso livre a partir do portal do Instituto de Literatura Comparada, organizada por Teresa Martins de Oliveira, Maria Antónia Gaspar Teixeira e Gonçalo Vilas-Boas (passagen.ilcml.com), que disponibiliza dados e traduções de textos de intelectuais e artistas refugiados em Portugal ou que por aqui passaram fugindo ao Holocausto e à perseguição nazi.

${ }^{4}$ Sobre a figura de Marianne Loring e, principalmente, para a versão portuguesa dos últimos capítulos da obra que aqui tratamos, vd. T.M.O. (2021), "Marianne Loring", in Passagen, https://passagen.ilcml.com/base/loring-marianne/. Vd., ainda, o verbete sobre Friedrich Stampfer na mesma base de dados.

${ }^{5}$ Existe uma tradução para português do Brasil, com o título Paisagens da Memória publicada em 2009 pela Editora 34.

${ }^{6}$ Para informações sobre Friedich Stampfer, vd. Passagen, https://passagen.ilcml.com/base/stampfer-friedrich/.

${ }^{7} \mathrm{O}$ episódio da deposição do SPD do governo da Prússia pelo governo do Reich (em 20.7.1932), que muitos consideram prenunciador da tomada do poder por Hitler, é recebido com uma surpreendente passividade, justificada pelos membros do partido com a valorização da legalidade. Com o partido comunista ilegalizado desde o incêndio do Reichstag (27.2.1933), cabe, todavia, a Otto Wels, líder do grupo parlamentar do SPD, o mérito de ter sido o único a opor-se à Lei de Plenos Poderes votada no Reichstag em 23.3.1932, que permitiu a Hitler estabelecer a sua ditadura.

${ }^{8}$ São principalmente grupos de sociais-democratas de orientação mais à esquerda, que se opõem a esta representação, sendo mesmo aqueles que inicialmente continuam a integrar a SOPADE gradualmente afastados ou silenciados. Numa primeira fase, 
e por influência da oposição interna (Neu Beginnen e Revoluzionäre Sozialisten Deutschlands), é publicado o Manifesto de Praga que apela a uma revolta armada contra Hitler, proposta bem diferente daquela advogada pela maioria do SOPADE, que cada vez mais se aproxima dos ideais de uma democracia liberal e parlamentar. Como exemplo daqueles que se declararam explicitamente contra as propostas do Manifesto, leiam-se publicações de Hilferding (1935) e quatro anos depois de Curt Geyer ( $v d$. Schilmar 2004: 54). As atas das reuniões da SOPADE encontram-se hoje publicadas, revelando as divisões e as múltiplas sensibilidades dentro do partido. Neste sentido, leia-se Der Parteivorstand der SPD im Exil. Protokolle der Sopade 1933-1940, bearbeitet von Marlies Buchholz e Bernd Rother; Projektleiter Obernaus e Hans-Dieter Schmid, J.H.W. Dietz Nachf, Bonn, 1995. ${ }^{9}$ É missão do SOPADE fixar a manutenção das estruturas partidárias, o apoio aos perseguidos políticos, a informação atualizada do estrangeiro acerca dos atos criminosos do regime nacional-socialista e o apoio às redes de resistência na Alemanha, estabelecendo "secretariados fronteiriços" em regiões limítrofes da Alemanha e publicando e distribuindo numeroso material propagandístico e informativo, entre ele o jornal Neuer Vorwärts [Novo Avante], do qual Friedrich Stampfer é editor. Ao mesmo tempo, o SOPADE desenvolve uma forte atividade programática, marcada pelo crescente distanciamento em relação ao marxismo e ao partido comunista, ainda que, pontualmente, tente estabelecer com este uma nunca concretizada aproximação tática, com vista à criação de uma frente unida de oposição ao nacional-socialismo (Plum 1970: 428-432).

${ }^{10}$ Sobre a relutância de muito dos membros do SPD no exílio em aceitar a representatividade do grupo de Praga e o papel conciliatório do Labour Party, vd. fes.de, cap.2, notas 103-106. De acordo com o mesmo texto, quando a presidência do partido no exílio se estabelece em Londres no início de 1941, viviam na Grã-Bretanha cerca de 160 exilados social-democratas.

${ }^{11}$ Estes capítulos encontram-se traduzidos na entrada relativa a ML na base de dados Passagen ( https://passagen.ilcml.com/ base/loring-marianne/.)

${ }^{12}$ Note-se que um leitor menos familiarizado com a geografia de Espanha irá estranhar a referência à viagem dos Stampfer de Madrid até Portugal com passagem por Valência. Trata-se, todavia, da vila raiana Valência de Alcântara, na província da Estremadura, e não da importante cidade Valência, situada na costa do Mediterrânio.

${ }^{13}$ Refiro-me aqui ao conceito tal como é explicado por Astrid Erll ( $v d$. Erll 2017).

${ }^{14}$ Leia-se, como exemplo, a seguinte passagem, que não pode deixar de chocar um leitor contemporâneo:

Wir kamen mit erheblicher Verspätung in Bordeaux an. Ein Zug von schwarzen Soldaten hielt vor uns, die alle in Bordeaux aussteigen sollten. Ich habe noch nie in meinem Leben so schwarze Menschen gesehen wie diese Senegaleser. Ich fragte mich, wie diese Menschen etwas von moderner Kriegsführung wissen können. Wissen diese halbtierische Menschen etwas von moderner Kriegsführung, wie man eine Kanone abfeuert? Ihre Wagen stanken wie Zirkuswagen, in denen wilde Tiere gehalten werden. (FaF, 32)

[Chegámos a Bordéus com um atraso considerável. Um comboio de soldados negros, que queriam desembarcar todos em Bordéus, parou à nossa frente. Nunca na minha vida tinha visto gente tão preta como estes senegaleses. Perguntei-me como podiam aqueles homens saber alguma coisa de uma guerra moderna. Será que estes homens meio animalescos sabem alguma coisa de como se faz uma guerra moderna, como se dispara um canhão? Os wagons deles cheiravam como carros de circo, em que se guardam animais selvagens.]

${ }^{15}$ Membro da União Pan-Europeia fundada por Coudenhove-Kalergi, Stampfer destaca-se pelo seu europeísmo ativo e pela sua luta pelos direitos da Alemanha na ordem europeia pós-guerra. Opõe ao nacionalismo de Hitler a criação de uma democracia baseada na igualdade, em que a soberania dos estados cederia força aos elementos construtores de uma unidade europeia, nomeadamente à unidade das culturas, à liberdade das relações económicas e à convergência no que respeita a questões de direito. A partir dos anos 40, e na qualidade de redator chefe do jornal Neue Volkszeitung, publicado em Nova Iorque, passa a defender a assunção por parte de França de um papel destacado numa futura federação europeia. Sobre o pensamento acerca da Europa de alguns dos membros do SPD, nomeadamente de Friedrich Stampfer e as referências textuais em que esta se encontra vertida, $v d$. Schilmar, 2004: 50-58; para Stampfer idem: 56-5. 


\section{Bibliografia}

Der Parteivorstand der SPD im Exil. Protokolle der Sopade 1933-1940, (1995) Herausgegeben und bearbeitet von Marlies Buchholz e Bernd Rother; Projektleiter Obernaus e Hans-Dieter Schmid, J.H.W. Dietz Nachf., Bonn.

Dogramaci, Burcu /Elizabrth Otto (2017), Passagen des Exils. Passages of Exil. München, text + kritik.

Gennep, Arnold van (2005), Übergangsriten (Les rites de Passages). Frankfurt a. M./N.Y., Campus Verlag [1909].

Loring, Marianne (1996), Flucht aus Frankreich 1940. Die Vertreibung der deutschen Sozialdemokraten aus dem Exil. Frankfurt a.M., Fischer, edição e prefácio de Wolfgang Benz.

Nünning, Ansgar (2010), "Memory's Truth" and "Memory's Fragile Power". Literature as a Medium for Exploring Fictions and Frames of Memory", in Fernanda Mota Alves et alii (orgs.), Filologia, Memória e Esquecimento - ACT 20. Lisboa, Humus, 417-453.

Oliveira, Teresa Martins de (2021a), "Marianne Loring", in Passagen, https://passagen.ilcml. com/base/loring-marianne/.

--(2021b), "Friedrich Stampfer", in Passagen, https://passagen.ilcml.com/base/stampferfriedrich/.

-- (2019), "Gretchen Wohlwill", in T.M.O e Maria Antónia Gaspar Teixeira, De passagem; artistas de língua alemã no exílio português. Porto, Afrontamento/ ILC-ML.

Passagen, Artistas e intelectuais de língua alemã no exílio português, Base de dados de acesso livre a partir do portal do Instituto de Literatura Comparada, organizada por Teresa Martins de Oliveira, Maria Antónia Gaspar Teixeira e Gonçalo Vilas-Boas (passagen.ilcml.com).

Plum, Günter (1970), "Volksfront, Konzentration und Mandatsfrage. Ein Beitrag zur Geschichte der SPD im Exil 1933-1939", in Vierteljahshefte für Zeitgeschichte, Jahrgang 18, Heft 4, online: Volksfront, Konzentration und Mandatsfrage (ifz-muenchen.de) (acedido em 7. 11. 2021).

Schilmar, Boris (2004), Der Europadiskurs im deutschen Exil 1933-1945. Oldenburg, De Gruyter.

Teixeira, Christina Heine (2001), "Lisboa, Símbolo de Esperança e de Liberdade: escritores alemães e austríacos em trânsito (1940-1941) algumas observações", in Arquipélago Revista da Universidade dos Açores, História, 2. ${ }^{\mathrm{a}}$ série, V, 669- 679.

Zylinski, Leszek (2011), Deutsche Schriftsteller und Europa. Oldenburg, BIS-Verlag. 